Filozofska fakulteta Univerze v Ljubljani

darja.mertelj@guest.arnes.si

\title{
POGOSTNOST IN RAZNOLIKOST PODREDNIH SKLADENJSKIH VZORCEV V KNJIŽEVNIH DELIH SETA IN LA LUNA E I FALÒ
}

\section{UVOD}

Da bi se lahko približali realni sliki skladenjske kompleksnosti v književnih besedilih, na katere naj bi gimnazija pripravljala dijake, je v nadaljevanju predstavljeno pojavljanje pogojnih, dopustnih in irealnih primerjalnih odvisnikov ter indirektnih odločevalnih vprašanj, pa tudi drugih, njim po pomenu ali obliki podobnih tvorb.

Za obširnejšo in bolj natančno preučitev sta bili izbrani dve književni deli, obe iz različnih vidikov primerni tudi za obravnavanje $\mathrm{v}$ ustreznih srednješolskih programih, ${ }^{1}$ kjer se dijaki učijo italijanščine kot tujega ali drugega jezika, vendar so razmisleki o raznovrstnosti skladnje in o pravilnem razumevanju elementov, ki se uporabljajo v tujih jezikih za izražanje vsebin zagotovo vredni razmisleka pri kateremkoli tujem jeziku, ki se ga učijo in v katerem na višjih stopnjah berejo tudi književna besedila slovenski dijaki oz. gimnazijci.

Preučitev večstavčne skladnje v obeh književnih delih, Seta in La luna e i falò, naj bi prikazala zastopanost (tj. pogostnost in raznolikost) štirih tipov odvisnikov $\mathrm{z}$ veznimi elementi se, anche se in come se, ki lahko uvajajo pogojne, dopustne in irealne primerjalne odvisnike ter indirektna odločevalna vprašanja. $V$ prispev$\mathrm{ku}$ je torej predmet preučevanja pojavljanje izbranih skladenjskih vzorcev v dveh italijanskih književnih besedilih (Seta, La luna e i falò): s preučitivijo pogostnosti in raznolikosti izbranih štirih podrednih skladenjskih vzorcev želimo pokazati skladenjsko kompleksnost v izvirnih italijanskih besedilih, ki naj bi se je učenci naučili obvladovati na ravni pravilnega razumevanja, večina pa naj bi to znanje s pridom uporabljala tudi kasneje (kot uporabniki italijanščine kot tujega jezika in/ali na drugih področjih svojega delovanja).

\section{PREDSTAVITEV OBEH KORPUSOV (SETA, LA LUNA E I FALÒ)}

Kratki sodobni italijanski roman Seta (Alessandro Baricco 1996; slov. naslov Svila, prevedla Maja Novak) je bil izbran zaradi njegovega velikega odmeva v svetu in

Književna besedila so bila primarno izbrana, ker naj bi bila po svoji raznovrstnosti in prepletanju tipov besedilnih odlomkov najverjetnejša slika realnosti in raznolikosti jezika. 
po izidu prevoda $\mathrm{v}$ slovenščini med slovenskimi bralci in kot besedilo, ki bi bilo zaradi svoje zgodbe in relativne kratkosti potencialno zanimivo za obravnavanje v gimnazijskih razredih. ${ }^{2}$ Celotno besedilo, ki obsega komaj 93 strani, je minimalistično in slogovno pretehtano pisanje. Zdi se, kot bi pisatelj želel z besedami orisati le ključne dogodke, da lahko bralec sledi nitim zgodbe, in zgolj nakazati smeri razmišljanja in čustvovanja junakov.

Daljši, povojni italijanski roman La luna e i falò (Cesare Pavese 1949; slov. naslov Luna in kresovi) pred petdesetimi leti preminulega pisatelja je bil izbran iz drugačnega razloga: kot daljše književno besedilo iz sodobne italijanske proze se je obravnaval na višji ravni maturitetnega preizkusa iz italijanščine kot tujega jezika (2003, 2004, 2005).

Celotno besedilo romana na približno 130 straneh in v 32 poglavjih je prežeto s spominjanjem prvoosebnega pripovedovalca na svoje otroštvo in odraščanje v Piemontu, na številne osebe in njihove življenjske zgodbe, ki se jih spominja, prepoznava in dopolnjuje ob svojem obisku v rodnih krajih (nekaj let po drugi svetovni vojni). Gre za pisanje iz časovne odmaknjenosti in vidika zrelega protagonista, ki je v vmesnem obdobju zrasel iz najstnika v zrelega moškega. Pisatelj je avktorialnemu prvoosebnemu pripovedovalcu dal vpogled tudi v razmišljanje in čustvovanje junakov.

\section{POGOJNI, DOPUSTNI, IREALNI PRIMERJALNI IN VSEBINSKI ODVISNIKI Z VEZNIKOM SE}

Cilj preučitve je bil pridobiti natančnejši vpogled v to, kateri od izbranih podrednih skladenjskih vzorcev se pojavljajo v obeh izvirnih književnih besedilih, in tudi, kako pogosti so. Pogostnost pojavitev bi lahko bila še dodatna, tehtna smernica za to, kaj se iz teh besedil nakazuje kot uporabno za gimnazijsko obravnavanje skladnje večstavčnih povedi. Poleg tega gre nenazadnje za italijanski književni deli, po kakršnih bi učenci (verjetno radi) posegli ob spodbudi in pomoči učitelja.

Kot je bilo nakazano v uvodu, so bile v celotnem besedilu romanov Seta (slov. Svila) in La luna e i falò (slov. Luna in kresovi) predmet preučitve podredno grajene povedi z eksplicitnimi odvisniki, ki jih uvajajo vezni elementi se, anche se in come se, pri čemer lahko navedeni vezni elementi uvajajo več tipov podrednih odvisnikov: pogojnega, dopustnega, irealnega primerjalnega in vsebinskega.

Pričenši s kratkim kvantitativnim pregledom o pogostnosti navedenih odvisnikov, lahko za roman Seta ugotovimo, da se je pojavilo 37 navedenih podrednih veznih elementov (gl. 1. prikaz) in še nekaj enakovrednih po sporazumevalni funkciji, npr. benché za izražanje dopustnosti, come in quasi pa za uvajanje irealnega primerjalnega odvisnika:

\footnotetext{
2 Obravnavanje $\mathrm{v}$ gimnazijskem razredu ni mišljeno $\mathrm{v}$ okviru priprav na maturo na višji zahtevnostni ravni. Odlomki iz romanov bi lahko - poleg drugih ciljev - služili za obravnavanje podrednih skladenjskih vzorcev.
} 


\begin{tabular}{|c|c|c|c|c|c|}
\hline & pogojni & dopustni & primerjalni & vsebinski & druge tvorbe \\
\hline $\begin{array}{c}\text { Izbrani vezni } \\
\text { element }\end{array}$ & se & $\begin{array}{c}\text { anchese } \\
0\end{array}$ & $\begin{array}{c}\text { comese } \\
10\end{array}$ & $\begin{array}{c}\text { se } \\
5\end{array}$ & $\begin{array}{c}\text { se } \\
1\end{array}$ \\
\hline $\begin{array}{c}\text { drugi vezni } \\
\text { elementi }\end{array}$ & $\begin{array}{c}\text { anche se } \\
1\end{array}$ & $\begin{array}{c}\text { benché } \\
2\end{array}$ & $\begin{array}{c}\text { come, quasi } \\
2\end{array}$ & $\begin{array}{c}\text { ni predmet } \\
\text { obravnave }\end{array}$ & $\begin{array}{c}\text { ni predmet } \\
\text { obravnave }\end{array}$ \\
\hline SKUPAJ & $\mathbf{2 1}$ & $\mathbf{2}$ & $\mathbf{1 2}$ & $\mathbf{5}$ & $\mathbf{1}$ \\
\hline
\end{tabular}

1. prikaz: Pogostnost izbranih odvisnikov in veznib elementov v romanu Seta

V bolj klasično napisanem romanu La luna e i falò pa se je pojavilo 75 zgoraj navedenih podrednih veznih elementov in še nekaj enakovrednih po sporazumevalni funkciji, npr. come, quasi za uvajanje irealnega primerjalnega odvisnika (gl. 2. prikaz).

\begin{tabular}{|l|l|l|l|l|l|}
\hline & pogojni & dopustni & primerjalni & vsebinski & druge tvorbe \\
\hline $\begin{array}{l}\text { Izbrani vezni } \\
\text { element }\end{array}$ & $\begin{array}{l}\text { se } \\
80\end{array}$ & $\begin{array}{l}\text { anche se } \\
4\end{array}$ & $\begin{array}{l}\text { come se } \\
8\end{array}$ & $\begin{array}{l}\text { se } \\
63\end{array}$ & $\begin{array}{l}\text { se } \\
10\end{array}$ \\
\hline $\begin{array}{l}\text { drugi vezni } \\
\text { elementi }\end{array}$ & $\begin{array}{l}\text { anche se } \\
1\end{array}$ & $\begin{array}{l}\text { se anche } \\
2\end{array}$ & $\begin{array}{l}\text { come } \\
7\end{array}$ & $\begin{array}{l}\text { ni predmet } \\
\text { obravnave }\end{array}$ & $\begin{array}{l}\text { ni predmet obrav- } \\
\text { nave }\end{array}$ \\
\hline & & benché & quasi & & \\
\hline SKUPAJ & $\mathbf{8 1}$ & $\mathbf{6}$ & $\mathbf{1 5}$ & $\mathbf{6 3}$ & $\mathbf{1 0}$ \\
\hline
\end{tabular}

2. prikaz: Pogostnost izbranih odvisnikov in veznih elementov v romanu La luna e i falò

Pogostnosti pojavljanja izbranih eksplicitnih odvisnikov po posamičnih veznih elementih je razvidna iz 3. prikaza: v romanu Seta (vsakič prvi od para stolpcev v 3. prikazu) se med navedenimi tipi odvisnikov in veznih elementov najpogosteje pojavljajo pogojni odvisniki $z$ veznim elementom se, zatem irealni primerjalni odvisniki z veznim elementom come se, sledijo jim vsebinski odvisniki z veznim elementom se (indirektna odločevalna vprašanja). Drugih veznih elementov za uvajanje pogojnega ali dopustnega odvisnika $v$ tem romanu ni bilo. 


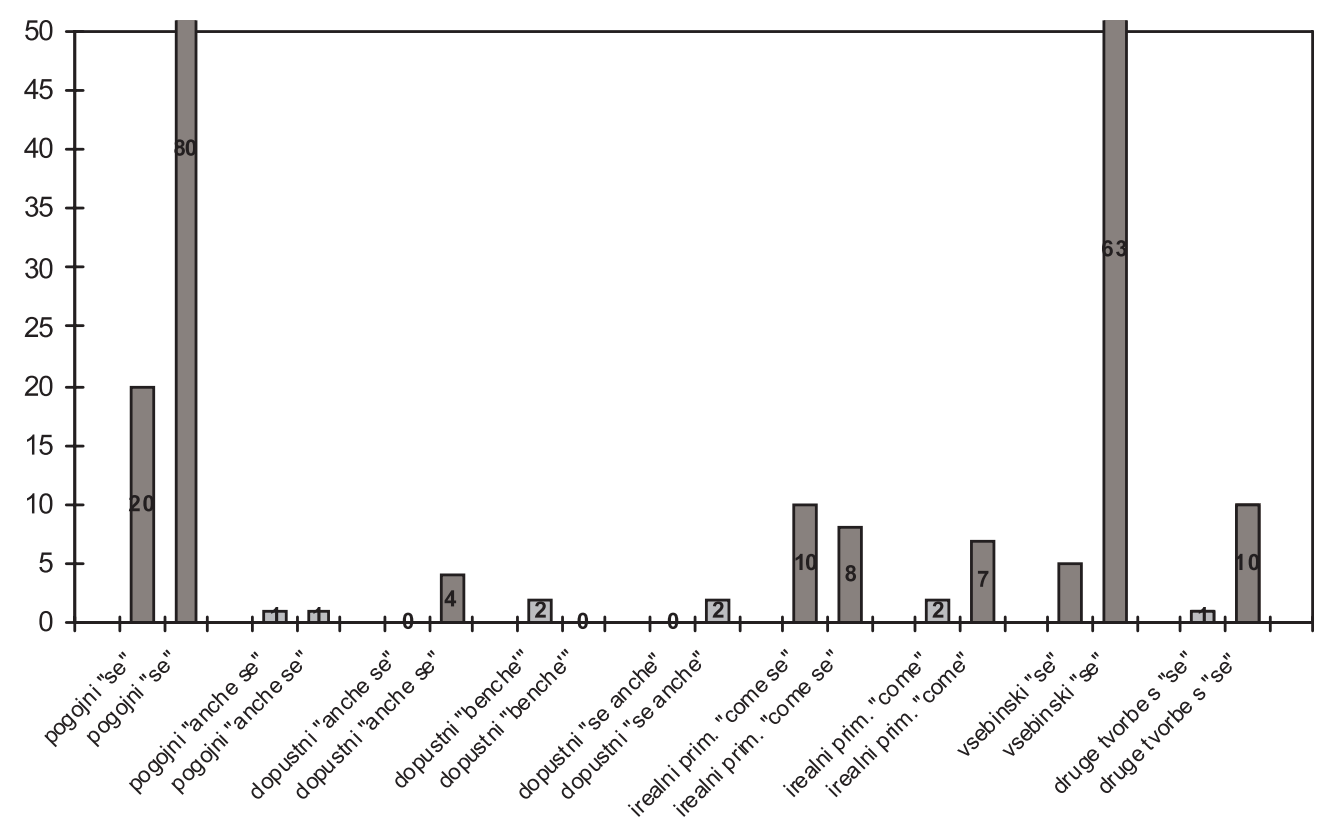

3. prikaz: Pogostnost izbranih odvisnikov v romanu Seta (prvi stolpec) in v romanu La luna e i falò (drugi stolpec)

$\mathrm{V}$ istem 3. prikazu je razvidna pogostnosti pojavljanja izbranih eksplicitnih odvisnikov v romanu La luna e i falò (vsakič drugi od obeh stolpcev v 3. prika$\mathrm{zu}$ ): najpogosteje se pojavljajo pogojni odvisniki z veznim elementom se, sledijo vsebinski odvisniki z veznim elementom se (indirektna odločevalna vprašanja) in zatem irealni primerjalni odvisniki $\mathrm{z}$ veznim elementom come se ter dopustni s skupno 6 pojavitvami. Od drugih veznih elementov za irealne primerjalne odvisnike je zastopan še veznik come.

Iz predhodnih številčnih in grafičnih podatkov lahko ocenimo, da bi se bralec minimalistično napisanega romana Seta srečal z enim od izbranih veznih elementov na skoraj vsaki drugi strani romana, kar nakazuje, da so navedeni vezni elementi oz. z njimi uvedeni odvisniki v tem romanu razmeroma sporadični. Po drugi strani pa se bo bralec romana La luna e i falò srečal z enim od izbranih veznih elementov in odvisnikov celo pogosteje kot na vsaki strani romana; navedeni vezni elementi oz. $z$ njimi uvedeni podredni odvisniki so $v$ tem romanu manj sporadični: njihova prisotnost je stalni izziv učencu, ki še razvija tovrstno znanje, da dojame njihov pomen.

V nadaljevanju prispevka so izpostavljeni primeri večstavčnih povedi, ki naj bi ponazarjali, da je težavnost pravilnega razumevanja povezana predvsem $\mathrm{z}$ raznolikostjo, ki se pojavlja v večstavčnih skladenjskih vzorcih. 


\section{Pogojni odvisniki z veznim elementom "se"}

\section{Roman Seta}

Pogojne odvisnike v romanu Seta uvaja vezni element se, drugi možni vezni elementi za uvajanje pogojnega odvisnika se niso pojavili, prav tako ne pogojna poved $\mathrm{z}$ elipso veznega elementa $\mathrm{v}$ odvisniku. ${ }^{3}$ Ena petina pogojnih odvisnikov (4 od 20) se pojavi v premem govoru protagonistov, npr.

1. (Baldabiou) Non c'è scelta. Se vogliamo sopravvivere, dobbiamo arrivare laggiù. (Ba 16)

Od skupno $16 \mathrm{v}$ premem govoru se jih 15 nanaša zgolj na realne pogoje in posledice $\mathrm{v}$ nepreteklosti protagonistov, npr.

2. (Hara K.) Se vorrete, mi piacerá vedervi tornare. (Ba 28)

Kar pet je takih, ki se kombinirajo $\mathrm{z}$ velelnikom $\mathrm{v}$ glavnem stavku, npr.

3. (Hara K.) Leggi il volo della tua freccia se vnoi sapere il tuo futuro, mi disse mio padre. (Ba 35)

Med vsemi pa je le en irealni pogojni odvisnik za nepreteklost, pa še ta je le delen, saj ima izpuščeno glagolsko obliko v glavnem stavku, tako da mora bralec intuitivno razumeti, da je manjkajoča glagolska oblika npr. ital. voglio, vorrei, richiedo:

4) (Hervé J.) Naturalmente niente sabbia, in mezzo, ma un giardino. E se fosse possibile teste di delfino, al posto di quelle di toro, all'entrata. (Ba 30)

$\mathrm{V}$ toku pripovedi pripovedovalca, $\mathrm{v}$ katerem se uporablja pripovedni postopek za preteklost, se je pojavilo 6 pogojnih povedi: dvoje se jih nanaša na irealnost v preteklosti, npr.

5. Se gliel'avessero chiesto, Hervé Joncour avrebbe risposto che [...] (Ba 11, Ba 93)

Dve pogojni povedi se nanašata na realni pogoj in posledico, npr.

6. Se cambiava vestito, la spostava in quello nuovo. (Ba 86)

Ena poved pa je poročana pogojna poved, za katero lahko le ugibamo oz. sklepamo iz konteksta, da je bila tudi prvotno irealna za nepreteklost (tj. Se non fosse per il parco, quest'anno potremmo morire di fame.):

7. Dicevano che se non fosse stato per il parco sarebbero morti di fame quell'anno. (Ba 81)

\section{Roman La luna e i falò}

V skladenjsko raznolikejšem književnem besedilu La luna e i falò se je v toku pripovedi prvoosebnega pripovedovalca pojavila približno polovica od 80 pogojnih povedi $v$ tem romanu, npr.

\footnotetext{
3 Druge oblike izražanja pogojnosti sicer niso bile predmet preučitve v romanu, vendar verjetno niso bile tako pomensko izrazite, da bi pritegnile mojo pozornost. Ni pa izključeno, da se je pojavil kakšen implicitni pogojni odvisnik, pogojni oziralni odvisnik ali nominalno izražanje pogojnosti.
} 
8) [...] io stesso, se di quella riva fossi stato il padrone, l'avrei magari roncata e messa a grano, ma intanto adesso mi faceva l'effetto di quelle stanze di città dove si affitta, si vive un giorno o degli anni, e poi quando si trasloca restano gusci vuoti, disponibili, morti. (Pa 11)

preostala polovica pa $\mathrm{v}$ premih govorih protagonistov, npr.

9) (Nuto) Serenate non ne ho mai fatte, diceva, una ragazza, se è bella, non è la musica che cerca. (Pa 16)

Enajst je tudi primerov, ko se pogojna poved pojavi kot del poročanega govora: take vložene pogojne povedi so se pojavljale v toku pripovedi prvoosebnega pripovedovalca, ki poroča govorna dejanja ostalih protagonistov, svojih sogovornikov, ${ }^{4}$ ki se izrazito pogovorno izražajo, npr.:

10) Allora io dissi che se il Valino tornava, lo aspettavo. Risposero insieme che delle volta tardava. ( $\mathrm{Pa} 29)$

Kot zanimivost naj omenim, da se je elipse veznega elementa se v pogojni povedi pisatelj poslužil le enkrat:

11) Non fosse stato della mamma vecchia e della casa che potevano bruciargli,

Nuto sarebbe andato anche lui nelle bande per aiutarla. (Pa 138)

\section{Realne pogojne povedi za nepreteklost in za preteklost}

Bralec naleti $\mathrm{v}$ romanu La luna e i falò na razmeroma številne realne pogojne povedi (skupaj 28), v katerih je v premih govorih protagonistov kombinacija glagolskih oblik $s e+P r+P r, s e+P r+I m p$., $s e+P r+F$ ali izpust glagolske oblike v protazi (primeri so v enakem vrstnem redu kot naštete kombinacije), npr.

12) (Cinto) Se la trovo le taglio la testa. (Pa 73)

13) (Nuto) Se sbaglio, correggimi. (Pa 74)

14) (Nuto) [...] Tanto se le cose non cambiano sarà sempre un disgraziato [...] - (Pa 42)

15) (Nuto) [...] Quest'è un paese che un discorso lo puoi fare soltanto in chiesa.

Se no, non ticredono $[\cdots]$ ( $\mathrm{Pa} 59)$

$V$ besedilu so tudi številne realne pogojne povedi za preteklost se+IM+IM (skupaj 20), ki niso pogovorna zamenljivka za irealno pogojno poved za preteklost $(s e+T P$ ' $+C C)$, npr.

16) [...] ci mettevamo tra le canne se era giorno, sulla proda della vigna, se c'era la luna, e bevevamo alla bocca discorrendo di ragazze. ( $\mathrm{Pa} 77$ )

\section{Irealne pogojne povedi za nepreteklost in za preteklost}

Irealne pogojne povedi v romanu La luna e $i$ falò so razmeroma pogoste tako $\mathrm{v}$ premih govorih protagonistov kot $\mathrm{v}$ pripovedi prvoosebnega pripovedovalca: skupno jih je 18 od 80 pogojnih povedi. Vendar se - kljub temu, da so protagonisti večinoma neizobražene osebe - dokaj pogosto pojavljajo konjuktivne oblike

4 Ni se pojavil primer, da bi bila pogojna poved vložena v premi govor enega izmed protagonistov, ki poroča o govoru drugega protagonista, kar bi bilo tudi možno. 
imperfekta in trapassata (IM', TP') v kombinaciji z obema kondicionaloma (C, CC), skupno v 14 povedih, in sicer v premih govorih protagonistov, npr.:

17) (jaz-prip.) Se il sor Matteo ce l'avesse fatto a noi quando andavamo nella riva, cos'avresti risposto? ( $\mathrm{Pa} 24)$

18) (Nuto) Se non fosse che è un toscano, direi che è un ignorante [...] (Pa 99)

ali v toku pripovedi prvoosebnega pripovedovalca:

19) Se di qui non fossi uscito per caso a tredici anni, quando Padrina era andata a stare a Cossano, ancor adesso farei la vita del Valino, o di Cinto. (Pa 30)

20) Se mi fossi ritrovato ragazzo, l'avrei percorsa un'altra volta. (Pa 49)

21) Se domani avessi dovuto scapparmene, nascondermi, per non farmi internare, mi sentivo già addosso la mano del poliziotto come l'urto del treno. (Pa 53)

Kot je razvidno iz primerov, prevladujejo irealne pogojne povedi tipa $s e+T P^{\prime}+C C$, ki se nanašajo na sfero preteklosti, neodvisno od tega, ali gre za preme govore ali za tok pripovedi. En primer (primer 18) se nanaša na sfero nepreteklosti, en pa na kombinacije pogoja $v$ preteklosti in posledice $v$ nepreteklosti (primer 19). Nekoliko izstopa primer 21 zaradi prislova 'domani' v kombinaciji s se+TP' (kar nakazuje visoko mero hipotetičnosti, pravzaprav odreka dogodku vsakršno možnost uresničitve); takoj zatem pa zaradi uporabe IM, ki ne sodi v hipotetično periodo: možni CC je izpuščen (npr. avrei preso molta paura) in z IM pisatelj le izrazi neprijetni občutek prijetja (ki ni hipotetičen).

Manj pogosta je pogovorna različica $s e+I M+I M$ kot pogovorna zamenljivka za irealne pogojne povedi za preteklost (ki bi jih sicer lahko izrazili s tvorbo $\left.s e+T P^{\prime}+C C\right)$, ki je zastopana $v 4$ tovrstnih pogojnih povedih, npr.:

22) No - disse Nuto - se ci andavo, mi bruciavano la casa. (Pa 24)

Poročane pogojne povedi - v vsebinski odvisnik vložene pogojne povedi

Tudi naslednji primeri v vsebinski odvisnik vloženih pogojnih povedi kažejo precej raznoliko sliko glede rabe glagolskih oblik v protazi in apodozi poročane pogojne povedi. $V$ spodaj navedenih povedih lahko $\mathrm{v}$ splošnem ugotavljamo, da odstopajo od tipične sheme che se $+T P^{\prime}+C C$, zlasti glagolske oblike v poročani protazi, kjer se npr. pogosto pojavi IM, npr.:

23) che se $+I M^{\prime}+C$ (razširjena sedanjost)

E fu allora che Nuto calmo calmo mi disse che superstizione è soltanto quella che fa del male, e se uno adoperasse la luna e i falò per derubare i contadini e tenerli all'oscuro, allora sarebbe lui l'ignorante e bisognerebbe fucilarlo in piazza. (Pa 44)

24) che se+Ger.I+CC

[...] Nuto una sera mi domandò com'era stato imbarcarmi per andare in America, se ripresentandosi l'occasione e i vent'anni l'avrei fatto ancora. (Pa 112)

25) che $s e+I M+I M$

[...] e perfino alla Mola cominciavano a dire che se non tornava c'era un motivo - si capisce, era incinta. (Pa 119)

26) che se+IM+CC (pogovorno)

Restammo d'accordo che, se il ragazzo metteva bene, a suo tempo gli avrei fatto io un posto a Genova. ( $\mathrm{Pa} 132)$ 
27) che se+IM+IM' (IM'v indirektnem velelnem stavku kot glavnemu stavku)

$[\ldots$.$] le disse che se avevano un fucile o una pistola li nascondessero nella riva. (Pa$ 137)

Vsak od teh primerov odstopa od sheme $s e+T P^{\prime}+C C$, ki jo predstavlja večina slovnic kot način poročanja pogojne povedi v preteklosti. Da bi povedi vseeno lahko pravilno razumeli, sta nujna opozorilo in komentar, morda tudi pretvorba $\mathrm{v}$ domnevno izvorno pogojno poved: pri tem pa ostaja dejstvo, da $\mathrm{v}$ teh primerih ne moremo biti prepričani glede tega, ali je bila prvotna pogojna poved (mišljena kot) realna ali irealna.

Kljub razmeroma velikemu številu raznolikih pogojnih povedi v obeh romanih, težko zaključimo, da je potencialna težavnost za slovenskega učenca (kot bralca izvirnika) majhna: poleg prototipičnih irealnih pogojnih povedi s $s e+I M^{\prime}+C$, $s e+T P^{\prime}+C C(s e+I M+I M)$ in s che se $+T P^{\prime}+C C$, se pojavljajo še druge kombinacije, npr. $s e+I M^{\prime}+C$ in $s e+T P^{\prime}+C$, ki so (trd) preizkus za bralca, ki želi ali potrebuje natančno razumevanje besedila.

Vsekakor je za doseganje pravilnega razumevanja nujna zavestna obravnava: raba glagolskih oblik v protazi in apodozi pogojnih povedi (ki $\mathrm{v}$ obeh besedilih sicer ne kaže večjih odstopanj od norme) je že sama po sebi kompleksna (realnost vs. irealnost, preteklost vs. nepreteklost). Navedeni zgledi kažejo, da mora slovenski učenec kot bralec izvirnika vložiti precejšen napor, da jih pravilno razume, zlasti v vidiku njihove časovnosti in naklonskosti.

\section{Dopustni odvisniki}

\section{Roman Seta}

Dopustni odvisniki z veznim elementom anche se se v romanu Seta niso pojavili, edini tak vezni element je imel dopustno-pogojno vrednost. V romanu sta se sicer pojavila zgolj dva eksplicitna dopustna odvisnika, uvedena $z$ veznim elementom benché, ki se nanašata na preteklost, in sicer $\mathrm{v}$ toku pripovedi pripovedovalca. Zanimivo je, da pisatelj z dopustnim odvisnikom, ki je prvi v daljši večstavčni povedi s prepletom številnih eksplicitnih in implicitnih odvisnikov, roman prične:

28) Benché suo padre avesse immaginato per lui un brillante avvenire nell'esercito,

Hervé Joncour aveva finito per guadagnarsi da vivere con un mestiere insolito, cui non era estraneo, per singolare ironia, un tratto a tal punto amabile da tradire una vaga intonazione femminile.

Per vivere, Hervé Joncour comprava e vendeva bachi da seta. (Ba 7)

29) slov.: Čeprav si je njegov oče zanj zamislil bleščečo vojaško kariero,

je Hervé Joncour nazadanje svoj vsakdanji kruh služil z nevsakdanjim poklicem. ki je bil po neki čudni ironiji tako prikupen, da je dajal slutiti rahel pridih ženstvenosti. Da bi preživel, je H. J. kupoval in prodajal sviloprejke. (No 9)

Druga poved, spet z veznim elementom benché, sodi v časovno sfero preteklosti. Za razliko od prve, $v$ kateri je pogoj $v$ dopustnem odvisniku preddoben glede 
na posledico v glavnem stavku, gre v drugem dopustnem odvisniku za istodobnost glede na glavni stavek:

30) Hervé Joncour rimase per ore tra le rovine del villaggio. Non riusciva ad andarsene benché sapesse che ogni ora, persa li, poteva significare disastro per lui, e per tutta Lavilledieu: $[\ldots]$ ( $\mathrm{Ba}$ 69)

31) slov.: [...] Nizmogel oditi, čeprav je vedel, da vsaka ura, ki jo zapravi tam, pomeni [...] (No 72)

Obe večstavčni povedi z dopustnim odvisnikom bi lahko opredelili kot skladenjsko zelo kompleksni in kot taki ne omogočata učencu enostavnega dostopa do polnega pravilnega razumevanja: $v$ ta namen bo moral prepoznati časovnost dogajanja (sfera preteklosti) in ob glagolih upoštevati aspektualnost glagolskih oblik v glavnih stavkih. ${ }^{5}$

\section{Roman La luna e i falò}

Tudi v romanu La luna e i falò so dopustni odvisniki izrazito redek pojav: trije so uvedeni $z$ veznim elementom anche se, dva $\mathrm{z}$ manj pogostim se anche in en $\mathrm{z}$ neanche se. Glagolske oblike v njih so v štirih primerih indikativne (PP, Pr, IM, IM) in imajo svoje prototipične vrednosti (za preddobnost in istodobnost v sedanjosti), npr.:

32) Nuto ba un modo di ridere fischiettando, anche se fa sul serio. (Pa 16)

in pri obeh IM istodobnost $\mathrm{v}$ preteklosti, npr.:

33) [...] me ne accorsi, via, anche se non capivo ancor bene. (Pa 94)

\section{Dopustno-pogojne povedi}

$\mathrm{V}$ romanu Seta je eden izmed odvisnikov v naslednji povedi uveden $\mathrm{z}$ veznim elementom anche se, ki ima vrednost veznega elementa za dopustno-pogojni odvisnik. Ta vrednost pa ni razvidna neposredno iz izbora glagolske oblike v apodozi:

34) Hervé Joncour rimase per ore tra le rovine del villaggio. Non riusciva ad andarsene benché sapesse che ogni ora, persa li, poteva significare disastro per lui, e per tutta Lavilledieu: non aveva nova di baco, con sé, e anche se le avesse trovate

non gli restavano che un paio di mesi per attraversare il mondo prima che si schiudessero, per strada, trasformandosi in un cumulo di inutili larve. (Ba 69)

35) slov.: [...]pa tudi če bi jib kje našel,

bi imel na voljo le kaka dva meseca, da obide svet. [...] (No 72)

Da bi lahko dojeli, da gre za irealni dopustni odvisnik, ki izraža preddobni pogoj v preteklosti, si moramo izbor imperfekta (IM) razložiti kot nadomestilo za sestavljeni kondicional (CC) v apodozi:

\footnotetext{
5 Nadalje bo moral prepoznati pomene veznih elementov in glagolskih oblik v odvisnikih in za pravilno razumevanje vedeti, ali je npr. v dopustnem odvisniku uporaba konjuktivne oblike posledica zgolj formalne prisile veznega elementa, ki ne kaže na neko hipotetičnost in bi ga lahko zamenjal z anche se, ki bi dopuščal uporabo indikativnega trapassata oz. indikativnega imperfekta (TP, IM) za slovenska 'približka': čeprav si je predstavljal oz. čeprav je vedel.
} 
36) $[\ldots]$, e anche se le avesse trovate non gli restavano che [...]

[npr. e anche se le avesse trovate non gli sarebbero rimasti più che un paio di mesi [...], op.p.

Podobni 'trdi orehi' se najdejo tudi v La luna e i falò: $\mathrm{v}$ dveh primerih, obeh $z$ veznim elementom se anche kot različico za anche se, sta prisotni konjuktivni obliki (TP') - v teh primerih gre za pomenske tvorbe, ki jih slovnice poimenujejo kot dopustno-pogojne odvisnike, čeprav bi jih po analogiji z irealnimi pogojnimi povedmi lahko poimenovali tudi irealni dopustni odvisniki :

37) Quella notte, se anche Nora si fosse lasciata rovesciare sull'erba, non mi sarebbe bastato. $(\mathrm{Pa} 20)$

38) (Nuto) [...] Se anche fossero stati fucilati per niente - disse -

toccava a lui fare la forza ai partigiani che sono morti come mosche per salvare il paese?(Pa 60)

Med dopustno-pogojne odvisnike je bil prvotno umeščen tudi naslednji primer:

39) Mi parve impossibile di averci tanto girato e giocato, da li alla strada,

di esser sceso nella riva a cercare le noci o le mele cadute,

aver passato pomeriggi interi con la capra e con le ragazze su quell'erba,

aver aspettato nelle giornate d'inverno un po' di sereno per poterci ritornare -

neanche se questo fosse stato un paese intero, il mondo. ( $\mathrm{Pa} 30$ )

Vendar v tem primeru ne gre za irealno dopustno poved, pač pa za irealno primerjalno, saj avtor primerja svoje ožje otroško in najstniško gledanje na svet $\mathrm{z}$ pogledom zrelega moškega. Italijanski lektor je poved oz. odvisnik prevedel $\mathrm{v}$ angleščino $\mathrm{z}$ veznim elementom as if ( $\mathrm{z}$ irealnim primerjalim odvisnikom), vendar pripomnil, da se s tem izgubi pomen čudenja pisca nad tem, kako je lahko mislil, da je svet njegovega otroštva ves svet. Neobičajno rabo veznega elementa neanche se je označil kot izrazito pogovorno, kot bi ne sodila $\mathrm{v}$ jezik protagonista.

\section{Irealni primerjalni odvisniki}

\section{Roman Seta}

Irealne primerjalne odvisnike v romanu Seta uvaja desetkrat vezni element come se in le dvakrat come (ta obakrat za enak opis okrasja prstov ene izmed protagonistk romana, Madame Blanche):

40) Alle dita, come fossero anelli, portava dei piccoli fiori di color blu intenso. (Ba 44, Ba 88)

Vezni element quasi, tudi možen kot uvajalec irealnega primerjanja, se ni pojavil. V besedilu sem zasledila tudi poved, ki vsebuje implicitni irealni primerjalni odvisnik:

41) Se la tenevi tra le dita, era come stringere il nulla. (Ba 29)

npr. [...] era come se stringessi il nulla. (op. p.) 
Irealno primerjanje stanj/dejanj se v tem romanu pojavi izključno v pripovedovalčevem diskurzu, saj se protagonisti v svojih premih govorih tega ne poslužujejo. Irealni primerjalni odvisniki sodijo torej v sfero preteklosti, in pri 10 od 12 irealnih primerjalnih odvisnikov gre za istodobnost stanj/dejanj glede na glavni stavek, ${ }^{6}$ npr.

42) Teneva gli occhi fissi sulle labbra di Hervé Joncour,

come se fossero le ultime righe di una lettera d'addio. (Ba 25)

Le v primeru dveh povedi je dejanje v irealnem primerjalnem odvisniku glede na glavni stavek preddobno, kar se ubesedi z uporabo konjuktiva trapasata (TP'): 43) Hervé Joncour non smise di parlare ma abbassò istintivamente lo sguardo su di lei

e quel che vide, senza smettere di parlare, fu che quegli occhi non avevano un taglio orientale, e che erano puntati, con un'intensità sconcentrante, su di lui:

come se fin dall'inizio non avessero fatto altro, da sotto le palpebre. (Ba 25)

44) Si alzò, ma rimase fermo, in piedi, come se avesse d'improvviso dimenticato dove stava andando. (Ba 99)

\section{Roman La luna e i falò}

Tudi petnajst irealnih primerjalnih odvisnikov Pavese v svojem romanu uvaja $z$ veznima elementoma come se in come v približno enaki meri $(8,7)$, pri čemer se vezni element come se pojavlja skoraj izključno v prvi polovici romana, $\mathrm{v}$ drugi polovici pa pretežno come. Izbor veznih elementov nima povezave z izražanjem istodobnosti ali preddobnosti hipotetičnega dejanja/stanja irealne primerjave, saj so rabe glagolskih oblik razpršene med oba. Razen enega se vsi irealni primerjalni odvisniki nanašajo na sfero preteklosti (in v okviru tega še nadalje na preddobnost), npr.

45) Nuto ascoltava con le labbra in fuori come avesse imboccato il clarino, e [...] (Pa 88)

V ostalih (dvanajstih) primerih pa gre za istodobnost v preteklosti, npr.

46) $[. .$.$] , e mi bevevo quei discorsi mentre giocavo con gli altri ragazzi,$

come se $i$ grandi li facessero per me. ( $\mathrm{Pa} 67)$

Edina istodobnost v sferi sedanjosti je del polpremega govora (nem. erlebte Rede, ital. discorso indiretto libero) prvoosebnega pripovedovalca:

47) Me li ricordo come fosse ieri. ( $\mathrm{Pa} \mathrm{89)}$

Tudi irealni primerjalni odvisniki so torej v romanu sporadični in ne morejo biti vir za naključno usvajanje: v svoji funkciji za izražanje irealne primerjave sicer ne morejo biti težavni za pravilno razumevanje, če je bil bralec o njih poučen, tako

\footnotetext{
6 Zanimivo je, da se $\mathrm{v} 7$ irealnih primerjalnih povedih $\mathrm{z}$ istodobnostjo dejanj/stanj glavnega stavka in odvisnika pojavljajo predvsem konjuktivne imperfektove oblike glagola essere (fosse, fossero) in po enkrat od drugih glagolov (stare, volere, ordinare). Ta pojav, če bi se pokazal tudi v drugih besedilih in v širšem naboru irealnih primerjalnih odvisnikov z istodobnostjo dejanj/stanj glavnega stavka in odvisnika, bi lahko morda imel pomenljivo didaktično aplikacijo in nakazal smer pristopa k poučevanju konjuktivnih oblik: poleg poučevanja principa tvorjenja oblike za poljubni glagol naj bi pri zahtevah glede produktivnega znanja lahko izhajali iz najpogostejših tipov tovrstnih povedi, tj. odvisnikov z glagolom essere in nekim dopolnilom.
} 
da lahko prepozna njihovo funkcijo in tudi obliko veznega elementa come kot enakovredno obliki come se.

\section{Vsebinski odvisniki z veznim elementom "se"}

\section{Roman Seta}

Indirektna odločevalna vprašanja kot podmnožica (predvsem) vsebinskih odvisnikov so v romanu Seta zastopana z enim primerom, in sicer v premem govoru protagonista (gre za časovno sfero nepreteklosti in zadobnost):

48) (Hara Kei) [...] Tu devi solo decidere se le venderò a voi, o a qualcun altro. (Ba 65)

Trije indirektni vsebinski odvisniki $\mathrm{z}$ veznim elementom se pa so del toka pripovedi pripovedovalca, vsi trije sodijo $\mathrm{v}$ sfero preteklosti in navedena dejanja $\mathrm{v}$ njih so glede na nadrejeni stavek istodobna:

49) Lo fece nella propria lingua, parlando lentamente, senza sapere con precisione, se Hara Kei fosse in grado di capire. (Ba 25)

50) Baldabiou comunicò agli allevatori di Lavilldieu che Pasteur era inattendibile, che quei due italiani avevano già truffato mezza Europa, che in Giappone la guerra sarebbe finita prima dell'inverno e che Sant'Agnese, in sogno, gli aveva chiesto se non erano tutti quanti un branco di cagasotto. (Ba 66)

in $\mathrm{v}$ enem primeru preddobna:

51) Baldabion gli chiese se aveva visto la guerra. (Ba 59)

V navedenih treh povedih oz. vsebinskih odvisnikih se pokaže, da Baricco ne uporabi v tovrstnih odvisnikih konjuktivnih glagolskih oblik vsakič. Nasprotno: konjuktivno obliko uporabi zgolj v primeru, ko je v povedi nakazana osebna negotovost protagonista $v$ zvezi s poročano vsebino $v$ odvisniku. Pri prvih dveh primerih pa $v$ kontekstu negotovosti ni, govor je o dejstvih in $v$ teh primerih pisatelj uporabi indikativne oblike.

\section{Roman La luna e i falò}

Izrazito drugačna je slika v La luna e i falò: vsebinskih odvisnikov z veznim elementom se (indirektna odločevalna vprašanja) je bilo okrog 60. Glede rabe glagolskih oblik v teh odvisnikih je bilo ugotovljeno, da je razmerje med indikativnimi in konjuktivnimi glagolskimi oblikami je povsem v prid prvih: $99 \%$ vs. $1 \%$.

Glede na zakonitosti rabe v zborni oz. knjižni italijanščini, kot jo opisujejo slovnice, je bilo pričakovati, da bi bilo to razmerje bolj medsebojno uravnoteženo. Zato je, glede na to, da gre za izobraženega pisatelja, tak velikostni razred po eni strani presenetljiv, po drugi pa ne: protagonisti so $\mathrm{v}$ primerjavi s prvoosebnim pripovedovalcem neizobraženi in bi bila uporaba konjuktiva iz njihovih ust slogovno neprimerna izbira za kontekst tega romana.

Prevladovali so glavni stavki tipa (v sferi preteklosti) Domandò se [...] (42 primerov), ki so jim sledili vsebinski odvisniki z imperfekti (IM) za izražanje istodobnosti (28 primerov), trapassati (TP) za izražanje preddobnosti (12 primerov) 
in sestavljeni kondicional (CC) za izražanje zadobnosti (2 primera). V besedilu je bilo tudi manjše število povedi (za sfero nepreteklost) tipa Chiede se [...], pri katerih so vsebinski odvisniki vsebovali pogosti set paradigem za nepreteklost: Pr za istodobnost, PP za preddobnost in F za zadobnost.

Konjuktivnih oblik se je v vsebinskem odvisniku (poročanem odločevalnem vprašanju) pojavilo le troje (manj kot en odstotek): en konjuktivni imperfekt z vrednostjo izražanja zadobnosti, pri katerem imamo tudi izpust glavnega stavka, ki bi se lahko npr. glasil $A l$ punto che diedi un'occhiata [...] per vedere [...], dejansko pa je poved taka:

52) [...] Al punto che diedi un'occhiata sotto il portico, dietro il fico, alle melighe, se comparissero Angelina e Giulia. ( $\mathrm{Pa} 28)$

in en konjuktivni trapassato za izražanje preddobnosti, npr.:

53 (Sapevo molte cose, gliele avevo chieste, ma non (sapevo, op. p.)

se lui avesse portato il fazzoletto rosso e maneggiato un fucile. ( $\mathrm{Pa} 24$ )

\section{Druge tvorbe $z$ veznim elementom "se"}

\section{Stopnjevanje}

Kot členke sem opredeljevala primere, ko je s se uvedena tvorba izražala stopnjevanje neke predhodno omenjene lastnosti. Pri primeru 5 (iz romana Seta), v katerem se pojavi vezni element se, gre za tako brezglagolsko tvorbo, ki je posledica izpusta nadrejene tvorbe, ki bi se $\mathrm{v}$ tem primeru glasila npr. približno [...] (razen) če ne rečemo, da je bila smešna. :

54) [...] in quella posizione, affatto singolare, se non addiritura ridicola. (Ba 97)

Seveda bi lahko to opredelili tuid kot neke vrste komentar k vsebini celotne povedi (gl. tudi Skubic 1999), vsekakor tak, kjer vsebini nadrejenega in podrejenega stavka s se nista neposredno povezani. ${ }^{7}$

\section{Izvzemalnost}

Pri spodaj navedenih primerih iz romana La luna e i falò, v katerih se pojavlja vezni element se, gre za brezglagolske tvorbe, ki so posledica elipse odvisnika, ki bi se v teh primerih glasil npr. približno [...] (razen) če ne štejemo / (razen) če ne izvzamemo [...]. Po smislu gre torej za neke vrste odvisnike ozira ali izvzemalne odvisnike, npr.:

55) Raccomandò di non andare a Cannelli se non per affari, [...] (Pa 58)

56) Non vedemmo nulla, se non la nebbia della luna. (Pa 115)

\section{Nominalizator}

O veznem elementu se v slovnični funkciji nominalizatorja govorimo takrat, ko se pojavi odvisnik, ki je le navidezno realni pogojni, po smislu pa ne: vezni element se v njemu namreč nima ene od svojih dveh prototipičnih vrednosti uvajalnega elementa za pogojni odvisnik ali za indirektno odločevalno vprašanje. Ima

\footnotetext{
Zahvaljujem se prof. T. Miklič za to jedrnato opredelitev (več o členkih v Skubic 1999).
} 
vlogo nominalizatorja, ki uvaja vsebinski odvisnik, ki bi ga npr. v slovenščini lahko uvedli z veznikom da (in le v bolj pogovorni različici tudi s če), npr.

57) Ci sarà una ragione se nessuno al mondo ha pensato di andare a comperare le nova laggiù. (Ba 19)

58) slov. Bo že razlog, (da)/ če šse nihče na svetu ni pomislil, da bi šel [...] (No 23)

$V$ takih primerih imamo po obliki pogojni (zaradi veznega elementa), po smislu pa vsebinski odvisnik. Podobni sta povedi v romanu La luna e i falò: navidezno realni pogojni povedi, ki pa ju po smislu ni mogoče umestiti med take:

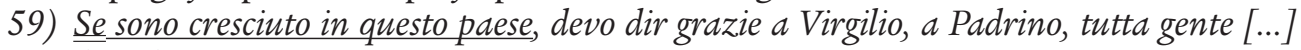
( $\mathrm{Pa}$ 9)

60) slov. Da / Če sem zrasel v tej vasi, se moram zahvaliti [...] (op.p.)

61) Ma se Santina camminava e correva, voleva dire che io [...] (Pa 74)

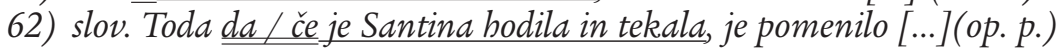

\section{DISKUSIJA IN UGOTOVITVE}

Na primeru izražanja logično-semantičnih odnosov pogojnosti, dopustnosti, irealnega primerjanja in navajanja odločevalnih vprašanj je v prispevku prikazano, kako so navedeni odvisniki po pogostnosti in raznolikosti zastopani v italijanskih romanih Seta (A. Baricco) in La luna e i falò (Cesare Pavese).

Glede pogostnosti pojavljanja izbranih skladenjskih vzorcev lahko ugotovimo, da so v Bariccovem minimalistično napisanem romanu Seta (Svila) izbrani odvisniki dejansko manj pogosti kot $\mathrm{v}$ Pavesejevem tradicionalno napisanem romanu La luna e i falò (Luna in kresovi). V obeh književnih besedilih je pogostnost izbranih štirih odvisnikov razmeroma nizka (razen realnih pogojnih odvisnikov). Kljub temu pa se v povedih romanov vsi konstantno pojavljajo: zastopani so $\mathrm{v}$ raznolikih kombinacijah $\mathrm{z}$ nadrejenimi in drugimi odvisnimi stavki, kar otežuje njihovo pravilno razumevanje.

Kljub minimalističnemu slogu pisatelja so v besedilu romana Seta prisotne tudi razmeroma številne večstavčne podredno in priredno grajene povedi. V njih se sicer redko, vendar $z$ določeno stalnostjo pojavljajo tudi odvisniki, ki so predmet preučitve tega dela: realni in irealni pogojni, dopustni, irealni primerjalni in vsebinski z veznim elementom se. Uvajajo jih vezni elementi, ki so pretežno v svoji značilni vlogi, posebne skladenjske tvorbe so redke.

$\mathrm{V}$ romanu La luna e i falò so podredno grajene povedi sorazmerno pogostejše, vendar tudi tu raba glagolskih oblik v protazi in apodozi pogojnih povedi, realnih in irealnih, ne kaže odstopanj norme. Med irealnimi pogojnimi povedmi prevladujejo tvorbe $s e+T P^{\prime}+C C$, ki se nanašajo na sfero preteklosti v toku pripovedi ali $\mathrm{v}$ premih govorih. Tvorba $s e+I M+I M$ se pojavlja kot realna pogojna poved ali pa kot pogovorna zamenljivka za irealne pogojne povedi v preteklosti. Dopustni odvisniki $\mathrm{z}$ anche se so $\mathrm{v}$ romanu redki. Glagolske oblike $\mathrm{v}$ njih so indikativne, $\mathrm{v}$ dveh primerih pa sta prisotni konjuktivni obliki (TP'), saj gre za dopustno-pogojno poved oz. irealni dopustni odvisnik za sfero preteklosti. 
Tudi irealni primerjalni odvisniki s come se so pri Paveseju in Bariccu razmeroma redki, uvajata jih $\mathrm{z}$ veznima elementoma come se in come $\mathrm{v}$ približno enaki meri. $V$ glavnem se nanašajo istodobnost ali preddobnost $\mathrm{v}$ sferi preteklosti. Vsebinski odvisniki s se so sicer sorazmerno pogosti, vendar ne morejo biti zgled slovenskemu učencu za rabo konjuktiva $\mathrm{v}$ vsebinskih odvisnikih $\mathrm{z}$ veznim elementom se, saj se $\mathrm{v}$ njih konjuktivne oblike $\mathrm{v}$ nasprotju $\mathrm{z}$ normo pisnega jezika pojavijo $\mathrm{v}$ zanemarljivi meri in odražajo govorjeni jezik manj izobraženih.

Pričakovanje torej, da bo $\mathrm{v}$ analiziranih besedilih njihova zastopanost (tako $\mathrm{z}$ eksplicitnimi kot z implicitnimi odvisniki) visoka, so je potrdilo torej le do neke mere: manj glede pogostnosti (kvantitativno) kot glede raznolikosti (kvalitativno). Glede pogostnosti v književni rabi jezika se je pokazalo, da so v analiziranem korpusu nekateri skladenjski vzorci sorazmerno redki, zlasti irealne pogojne povedi in irealno primerjanje. Sklepam lahko, da so torej potrebe pisateljev po izražanju določenih logično-semantičnih odnosov z odvisniki sporadične. Vendar izsledki o zastopanosti (pogostnosti in raznolikosti) porajajo tudi dvome, saj se je potrebno zavedati:

a) da je ocena tega, ali gre za redek ali pogost pojav v jeziku, vendarle do precejšnje mere osebne narave: marsikateri jezikoslovec bi verjetno ocenil ugotovljene pogostnosti izbranih 4 odvisnikov v izvirnih besedilih kot relativno visoke, še zlasti če jih primerja $z$ kakšnim leksikalnim izrazom; in

b) da je celo izbor relativno obsežnega korpusa besedil z vidika možne pogostnosti določenih odvisnikov vendarle subjektivne narave: podobno obsežen, vendar vsebinsko drugačen korpus bi lahko nakazal povsem drugačne vrednosti: morda celo z bistveno nižjo ali bistveno višjo zastopanostjo istih tipov odvisnikov.

\section{Glotodidaktične implikacije}

Pri preučitvi dejanske rabe se je pokazalo, da se vsi preučevani odvisniki v obeh italijanskih književnih besedilih konstantno pojavljajo, čeprav pogostnost nekaterih ni visoka. Zato menimo, da

- zgolj branje izvirnih besedil, ki praviloma izkazujejo le sporadično pojavljanje omenjenih skladenjskih vzorcev, ne more tvoriti ustrezne osnove za njihovo usvajanje, vendar se bo slovenski učenec kot bralec takih izvirnih besedil z njimi soočal;

in

- da zgolj intuitivno pravilno dojemanje ne more biti zagotovilo, da se ne bo pojavila negotovost učenca ali nepravilnosti pri rabi, zato naj ostanejo ali postanejo odvisniki predmet zavestnega poučevanja s ciljem, da jih učenec $v$ tujejezikovnih besedilih zmore pravilno razumeti, ko se pojavijo oz. da jih v okviru lastne komunikacije zna ustrezno uporabiti.

Zastavlja se vprašanje, ali je smiselno in ekonomično investirati šolski čas in napore gimnazijcev za nekaj, kar bodo morda potrebovali na ravni razumevanja relativno redko in na ravni tvorjenja besedil (večina) morda celo nikoli. Nikakor pa tudi ne moremo zaključiti, da so tu preučeni odvisniki tako redki, da bi jih 
pri poučevanju zanemarili ali celo ne obravnavali. V gimnazijskem razredu naj bodo torej vsaj prototipične oblike in rabe izbranih skladenjskih vzorcev predmet zavestnega poučevanja, saj te že zaradi razlik s slovenščino v rabi tipa odvisnika, veznega elementa in/ali glagolske oblike učencem povzročajo težave (negativni transfer iz slovenščine). ${ }^{8}$

Prav zaradi obeh navedenih subjektivnih vidikov menim, da je nujno ne le ohraniti sedanjo raven poučevanja skladnje, temveč v gimnazijah ponovno uvesti oz. povečati eksplicitno poučevanje skladnje večstavčnih povedi, s čimer bi se učencem omogočilo tudi razvijanje takih učnih strategij, ki pomenijo prispevek k dinamičnemu procesu vseživljenjskega učenja tujega jezika.

To se zdi sicer deloma v nasprotju s splošnimi usmeritvami na področju tujejezikovne didaktike: snovalci učbenikov italijanščine kot tuji/drugi jezik se namreč ravnajo po Skupnem evropskem jezikovnem okviru (2001, slovenski prevod izide 2011), plodu skupnih evropskih prizadevanj, tako da jim konceptualne in splošne didaktične nedomišljenosti ne moremo očitati, morda le preveč implicitno nakazano pomembnost povezave med slovničnim znanjem in obvladovanjem štirih zmožnosti. ${ }^{9}$

\section{BIBLIOGRAFIJA}

\section{Primarni viri (korpus) - izvirna književna besedila}

BARICCO, Alessandro. 1996. Seta. Milano: Rizzoli (BUR).

BARICCO, Alessandro. 1997 (prevod v slov., M. Novak). Svila. Ljubljana: Vale-Novak.

PAVESE, Cesare. 1949. La luna e i falò. Milano, Torino: Einaudi, Mondadori.

\section{Sekundarna bibliografija}

AA. VV. (2002) Quadro Comune Europeo di Riferimento per le Lingue : apprendimento, insegnamento, valutazione, Consiglio d'Europa - Firenze, La Nuova Italia O.U.P. http://www.coe.int/T/DG4/Linguistic/Source/Framework_EN.pdf FAVA, Elisabetta (1991) Interrogative indirette. V: L. Renzi in G. Salvi (ur.), Grande grammatica italiana di consultazione: Vol. II. Bologna: il Mulino. [675-720]

MAZZOLENI, Marco (1991a) Le frasi concessive. V: L. Renzi in G. Salvi (ur.), Grande grammatica italiana di consultazione : Vol. II. Bologna: il Mulino. [784-817]

\footnotetext{
8 Zavedati se moramo, da je v italijanščini pri odvisniku/ih v večstavčnih povedih razlog za precejšnjo (oblikovno) pestrost pri izražanju posameznega logično-semantičnega odnosa z nekim odvisnikom prav kombinacija med veznimi elementi in 15 italijanskimi osebnimi glagolskimi oblikami, med katerimi je treba (znati) izbirati (gl. Miklič 1992, 1994, 2001, 2003, 2004).

9 Okvir ne poglablja specifičnosti v poučevanju/učenju posamičnih jezikov, vendar pa z opredelitvami ciljev oz. opisi ravni znanj vpliva na to, da postajajo učbeniki za različne tuje jezike (morda preveč) podobni, celo učbeniki založb za isti tuji jezik. Ob snovanju učbenikov (ko komercialni razlogi praviloma prevladajo nad voljo do upoštevanja specifičnosti) se premalo upošteva dejstvo, da gre kljub enakim ciljnim ravnem znanj/a za poučevanje različnih tujih jezikov v skupinah učencev, ki imajo različna jezikovna izhodišča (slovenski vs. španski učenci, ki se učijo italijanščine). Pri različnih jezikih so do neke mere gotovo potrebni različni ali na nekaterih področjih specifični načini ter različen čas za dosego istih sporazumevalnih ciljev.
} 
MAZZOLENI, Marco (1991b) Le frasi ipotetiche. V: L. Renzi in G. Salvi (ur.), Grande grammatica italiana di consultazione : Vol. II. Bologna: il Mulino. [751-784]

MERTELJ, Darja (2005) Poučevanje nekaterih podrednih skladenjskih vzorcev pri predmetu 'italijanščna' kot tuji jezik $v$ slovenskih gimnazijah : sedanje stanje in predlogi za spremembe (it. L'insegnamento di frasi complesse nell' ambito dell'italiano come lingua straniera nei licei sloveni: stato attuale e proposte). Doktorska disertacija. Ljubljana: Filozofska fakulteta, Oddelek za romanske jezike in književnosti.

MERTELJ, Darja (2008) Ravni znanja večstavčne skladnje pri učencih zitalijanščino kot tujim jezikom. V: Skela, J. (ur.), Pregled stanja tujejezikovnega učenja in poučevanja $v$ Sloveniji z vidika evropskih usmeritev in predlogov nadaljnje konceptualizacije poučevanja tujih jezikov. Ljubljana: Filozofska fakulteta, 348-369.

MIKLIČ, Tjaša (1992) Tendenze nella scelta delle forme verbali italiane in testi prodotti da apprendenti sloveni: in cerca di spie dell'interferenza. V: B. Moretti, D. Petrini in S. Bianconi (ur.), Linee di tendenza dell'italiano contemporaneo. Roma: Bulzoni, 475-492.

MIKLIČ, Tjaša (1994) Eksplicitno kontrastiranje principov ubesedovanja logičnosemantičnih relacij pri pouku tujega jezika: problem izražanja pogojenosti v različnih jezikih. Uporabno jezikoslovje, (3), 84-98.

MIKLIČ, Tjaša (2001) Raba slovenskih glagolskih oblik v luči časovnosti, dobnosti, vidskosti in naklonskosti. V: S. Orel (ur.), Zbornik predavanj : 37. seminar slovenskega jezika, literature in kulture. Ljubljana: Center za slovenščino kot drugi/ tuji jezik pri Oddelku za slovanske jezike in književnosti Filozofske fakultete. [301-318]

MIKLIČ, Tjaša (2003) Interpretazione della funzione testuale dei paradigmi verbali italiani. Tentativo di un modello d'analisi integrata. V: M. Giacomo-Marcellesi M. in A. Rocchetti (ur.), Il verbo italiano: Studi diacronici, sincronici, contrastivi, didattici. Roma: Bulzoni, 553-570.

MIKLIČ, Tjaša (2004) Testi narrativi, azioni centrali e paradigmi verbali italiani. V: Paolo D’Achille (ur.), Generi, architetture e forme testuali. Firenze: F. Cesati, 145-160.

MIKLIČ, Tjaša / Martina OŽBOT (2007) Teaching the uses of Italian verb forms to Slovene speakers, Linguistica XLVII (1), 65-76.

SKUBIC, Andrej (1999) Ogled kohezijske vloge slovenskega členka. Slavistična revija, 47 (2), 211-238.

WANDRUSZKA, Ulrich (1991) Frasi subordinate al congiuntivo. V: L. Renzi in G. Salvi (ur.), Grande grammatica italiana di consultazione : Vol. II. Bologna: il Mulino. [416-481] 


\section{POVZETEK}

\section{Pogostnost in raznolikost podrednih skladenjskih vzorcev v književnih delih Seta in La luna e i falò}

Skladenjsko kompleksne povedi so pogosto vitalni del književnega jezika. Namen tega prispevka je predstaviti skladenjsko raznolikost dveh italijanskih daljših književnih besedil, primernih tudi za obravnavanje v srednješolskem okolju, in nakazati morebitne jezikovne težave, ki bi jih lahko imeli slovenski učenci zaradi skladenjske raznolikosti. Analiza se osredotoča na podredne stavke, ki jih uvajajo vezniki se, anche se in come se in ki lahko uvajajo različne odvisnike: večina je takih, ki slovenskemu in drugim slovanskim učencem italijanščine povzroča težave zaradi interferenc pri izboru ustrezne glagolske paradigme v odvisniku. Pokazalo se je, da se vsi obravnavani tipi odvisnikov pojavljajo v obeh italijanskih romanih Seta (slov. Svila) in La luna e i falò (slov. Luna in kresovi) z določeno stalnostjo, vendar jih ne moremo opredeliti kot zelo pogoste. Zaradi svojega sorazmerno sporadičnega pojavljanja, toda visoke raznolikosti, ne morejo tvoriti stabilnega vnosa za učence: uspešnost nezavednega usvajanja ni zelo verjetna. Potrebno je zavestno učenje zaradi drugačnih zakonitosti pri izbiri jezikovnih sredstev v obeh jezikih. Izsledki analize predstavljajo dodaten razlog, da naj bi bili v zavestno poučevanje in učenje italijanščine kot tujega jezika vključeni vsaj najpogostejši in prototipični tipi odvisnikov.

Ključne besede: skladnja zložene povedi - italijanska književna besedila - vezniki se, anche se, come se - slovenski učenci italijanščine

\section{ABSTRACT}

\section{The frequency and heterogeneous nature of complex clauses in the literary texts Seta and La luna $\mathrm{e}$ i falò}

Syntactically complex clauses are often a vital part of literary language. The aim of this paper is to present the syntactically heterogeneous nature of two longer Italian literary texts selected as being suitable for reading at high school, and to highlight potential difficulties Slovenian learners may have when dealing with them. The analysis focuses on subordinate clauses introduced by the conjunctions se, anche se and come se which can introduce various subordinate clauses most of which are notorious for Slovenian and other Slavic learners of Italian due to interferences in the area of the appropriate use of verbal forms in subordinates. It was found that all the subordinates dealt with constantly appear in the Italian novels Seta and La luna e i falò, but they cannot all be defined as very frequent. Due to their relatively sporadic appearance but highly heterogeneous nature they cannot represent a stable input for learners: successful unconscious acquisition is not very likely. Instead, conscious learning appears to be necessary due to the different principles governing the choice of tenses in the two languages. Accordingly, the most frequent and prototypical syntactic patterns (subordinates) should be included in conscious learning/teaching of Italian as a foreign language.

Keywords: syntax of complex clauses, Italian literary texts, conjunctions se, anche se, come se, Slovenian learners 